\title{
Development and Indicators of Multifunctional Autonomous Plants Using Renewable Energy Sources
}

\author{
Vladimir I. Kabakov ${ }^{1}$ \\ ${ }^{1}$ JSC “ENIN”, 19 Leninsky prospect, Moscow, Russia \\ Correspsondence: Vladimir I. Kabakov, PhD, Assistant Professor, JSC "ENIN", 19 Leninsky prospect, Moscow, \\ 119991, Russia. Tel: 7-495-770-3418. E-mail: vikab@eninnet.ru \\ Received: July 16, 2014 \\ doi:10.5430/jms.v5n3p51 \\ Accepted: August 6, 2014 \\ Online Published: August 12, 2014 \\ URL: http://dx.doi.org/10.5430/jms.v5n3p51
}

\begin{abstract}
The autonomous plants using the solar and geothermal energy were developed and designed in ENIN. The plants are intended for solving the concrete regional problems and allow to lift the water from the sources or wells of different depth (up to $20 \mathrm{~m}$ and more), including the pure water and the water with particles or the brine, and supply also the steam and heated water to consumers in the places, which are remote from water supply and district heating system. The other purposes were: a removal of heat and chemical environmental impact, decreasing mineralization or desalination of mineralized water etc. The common feature of plants under consideration was the application of jet pumps (condensing injectors), which have the different constructions but combine simultaneously the vacuum and delivery pump as well as the condenser and heat exchanger. It was shown that in the conditions under consideration the use of such plants is economically profitable.
\end{abstract}

Keywords: plants using renewable energy, water and heat supply, solar water-lifting, geothermal heat supply, method of calculation, field tests, multifunctional application

\section{Methods of Calculating the Plants and Their Elements}

The solar and geothermal plants with one jet pump are mainly considered in this article. The theoretical study and the experimental results of investigating physical processes as well as of laboratory and field tests of jet pumps (JP) and other elements of plants, on the basis of which the methods of calculating these elements and plants were developed on the whole, are briefly described and had as a purpose the improvement of their characteristics (Kabakov V.I., Zheltova G.M., 1988, pp. 139-150).

The theoretical and experimental studies of jet pump and receiver of solar energy of parabolic trough (PT) (Kabakov V.I., Usanov V.V., 2003, pp. 89-105 and Kabakov V.I., Kokhova I.I., Drobiazgina O.N., 1989, no. 3) had the goals to install the connections between operating and geometrical parameters of plants elements. The plants operation was tested and analyzed at the laboratory benches and then under the field conditions in Crimea (at the territory if SES-5), in Makhachkala (Dagestan), Bukhara, Yangi-Yull and Fergana (Uzbekistan) and at the waste wells of Pauzhtskoye geothermal field, which were not used anymore because of their low flow rates for operating Geo TPP. After it the solar plant with parabolic troughs in Fergana and the geothermal plant at Pauzhetka (Kamchatka) were created and had successfully operated (Kabakov V.I., Yeroshenko V.M., 2012, pp.39-44 and Trusov V.P., Kabakov V.I., Sorokin A.I, Shabanov A.A, Milman N.A., 1995, pp. 2119-2124).

The first solar plant using the flat solar heaters-collectors is shown in Figure 1. Though this plant was operating in the intermittent duty (the accumulation of steam in solar heaters under solar energy effect during 15 minutes and the time with same duration for stimulating the water lifting), but it was important that a possibility for using the jet pumps for pointed purposes was first confirmed. 


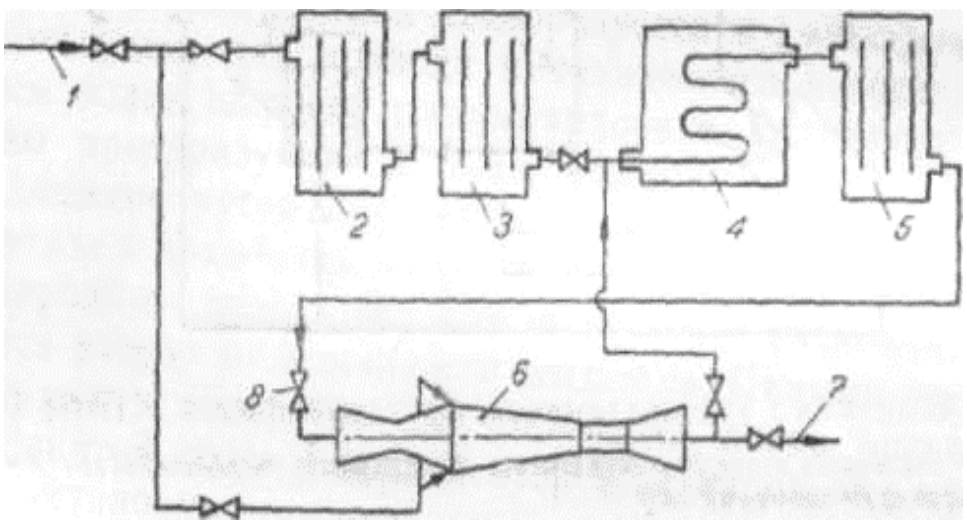

Figure 1. Schematic diagram of solar water lifting plant with flat heaters and jet pump in Bukhara: 1 - water pipeline; 2, 3 и 5 - solar collectors of Bukhara works for helio-devices; 4 - solar heater of pipe type; 2 and 3 - with single glazing; 5 - with double glazing; 6 - laboratory jet pump-injector; 7 - to consumer; 8 - пусковой вентиль

As to the method used in JP calculations for such flow rates and pressures, the same theoretical approach (one-dimensional theory) was used on the whole as in developing and designing laboratory constructions (Kabakov V.I., Zheltova G.M., 1988, pp. 139-150). The conservation equations and, first of all, the momentum conservation equation allowed to obtain the dimensional equations connecting the main regime and geometric parameters. If to introduce the dimensionless numbers:

$$
\mathrm{Z}=\left[\left(p_{\text {еx }}-p_{\mathrm{mc}}\right) / \rho_{2} w_{2}^{2}\right][(1+u) /(u+\omega)]^{2} ; \mathrm{u}=G_{2} / G_{1} ; \omega=w_{1} / w_{2} \text { и } Y=\left[F_{2}(1+u)_{2}\right] /\left[F_{\text {гд }}(u+\omega) u\right],
$$

where $p_{\text {ex }}$ и $p_{\mathrm{mc}}$ are the pressures at the exit from diffuser and in mixing chamber; $w_{1}$ and $w_{2}$ are the velocities of steam-ware mixture and liquid at the entrance in JP mixing chamber; $G_{1}$ and $G_{2}$ are the flow rates corresponding to them; $\rho_{2}$ is a liquid density; $F_{2}$ and $F_{\mathrm{dt}}$ are the area occupied by liquid at the mixing chamber-and the area of diffuser throat, the momentum conservation equation takes a view $Z=Y(Y-1 / 2 Y)$. Then $p_{\mathrm{ex}}-p_{\mathrm{mc}}=\rho_{2}\left(w_{1}{ }^{2} / 2\right) k_{\mathrm{cm}} \cdot\left(2 Y-Y^{2}\right)$, where $k_{\text {mix }}$ is a coefficient that accounts the mixing loss and more is as less are $u$ and $\omega(\omega \rightarrow 1)$.

All main values and parameters of construction and operation of the main elements were used for analyzing the experimental results and optimizing JP both in laboratory and field tests. In the same time they were used together with the efficiency values obtained during the laboratory tests of injectors and their separate elements, in the calculation and design of new JP with large throughputs for Pauzhetskoye geothermal field and the small JPs for Fergana. As it was pointed out, the technical solutions protected by authorized certificates and patents as well as the results of studying in ENIN laboratory of separate elements and processes in them were taken into consideration in the injectors design. The test unit for investigation of laboratory constructions of injectors and jet pump JP-312 at Kamchatka is shown in Figure 2.

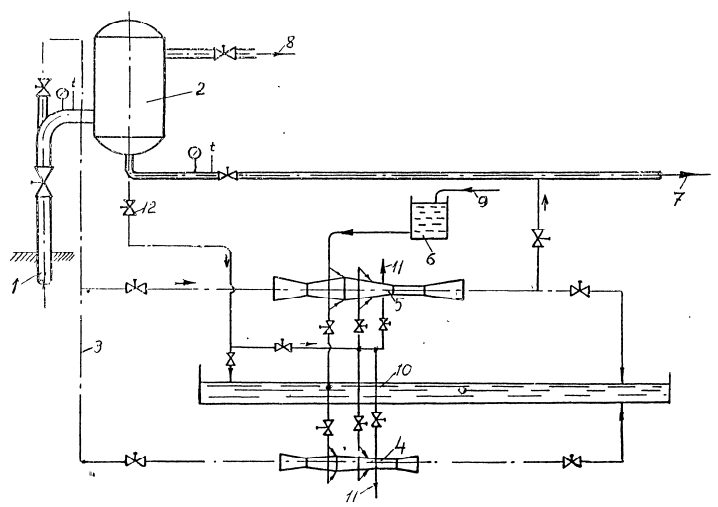

Figure 2. Test unit at a well RE-1 of Pauzhetskoye geothermal field: 1 - geothermal well RE-1; 2 - separator; 3 steam-water mixture; 4 - laboratory injector; 5 - jet pump JP-312; 6 - starting tank; 7 - in a system of hot ware and heat supply; 8 - to GeoTPP; 9 - mountain stream; 10 - small river; 11 - discharge in atmosphere during startup; 12 outlet of thermal water (brine) after separator 

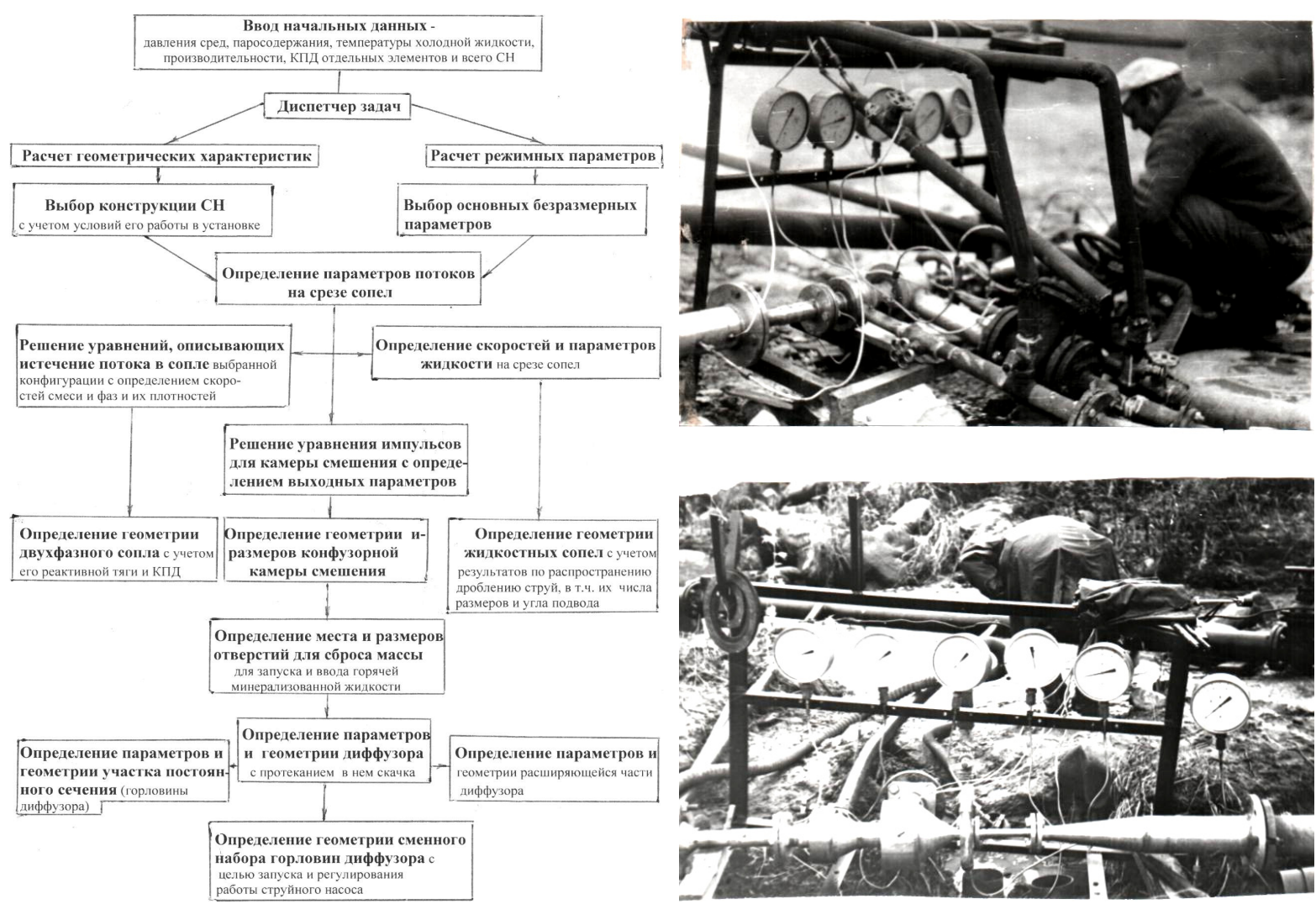

Figure 3. Photos of tested pump JP-312 at Kamchatka and generalized block-diagram for determining the geometric parameters of injectors and operating parameters of geothermal and solar plants

The generalized block diagram for determining the operation parameters of geothermal and solar plants as well as the photographies of tested pump JP-312 at geothermal well RE-1 are presented above in Figure 3.

The different schemes of plants for multifunctional use were developed and patented including: the desalination, environmental protection, reduction of liquid mineralization of water supplied to consumer, reinjection of brine in the field's stratum etc., i.e. for solving the concrete main (water lifting - heat supply) and associated problems at the place.

The sizes of jet pumps for the concrete parameters of steam-water mixture and liquid for solar plant in Fergana and geothermal plant at well K-16 were determined using the method shortly described in this section.

The tests of jet pump JP-312 - the first one developed by means of mentioned method and studied in details at the well RE-1 and K-16 are presented furthermore in Figure 7. The agreement between the experimental and calculated (curves) results for JP CH-312 as well as for two other large JP was quite satisfactory (Kabakov V.I., 2006, Chiba, Japan).

\section{Solar Plant with Jet Pump for Water- and Heat Supply}

The special interest to solar thermodynamic plants with concentrators after some interval is connected with the improvement of separate elements and entire technology, namely, with the developments fulfilled last time (Kabakov V.I., 2014, pp. 12-17). Some of these improvements became or repeat the developments or application of the results obtained at the small-scale parabolic trough plant in Fergana (Kabakov V.I., Yeroshenko V.M., 2012, pp. 39-44). Improvement of optical part, the measures on increasing efficiency of conversion part of plants, optimization of schematic solutions (photothermodynamic variant) as well as the application of heat accumulators made the usage of concentrating plants more efficient.

It should be noted that in addition to the mentioned positive moments the results of studying processes were used as well on the large plants with renewable. The same way was chosen by USA and Spain, where the developments and investigations at small plants-prototypes always precede to the construction of large plants. The working media and 
elements as well as the functioning and efficiency of all the system on the whole were determined at the small plants-prototypes.

One of such plants-prototypes of the larger plant was the plant with parabolic trough (PT) in Central Asia (Fergana). In all our plants with PT the jet pump is located after the heat collecting element (Kabakov V.I., Kokhova I.I., Drobiazgina O.N., 1989, 4]. The photography of plant, jet pump and control desk are presented in Figure 4.
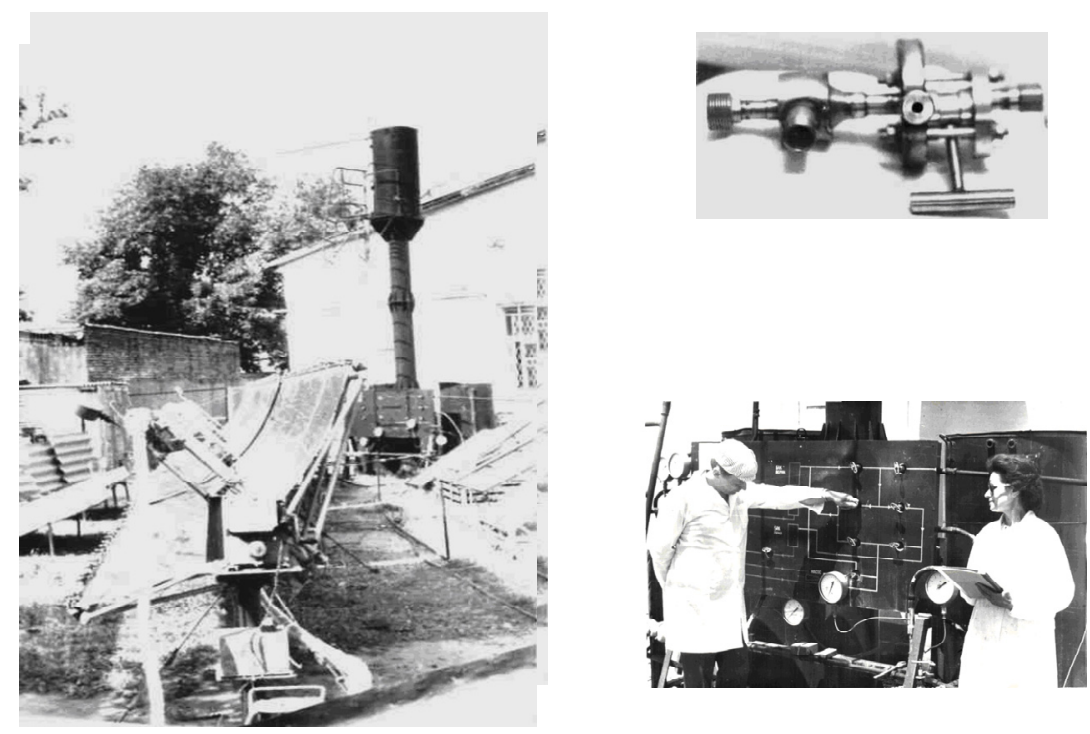

Figure 4. Overall view of solar plant, jet pump and control desk

Figure 5 shows the variant of solar plant, which in addition to PT and JP contains the photovoltaic array installed on the first module of PT-receiver and also the usual submerged pump with electric drive.

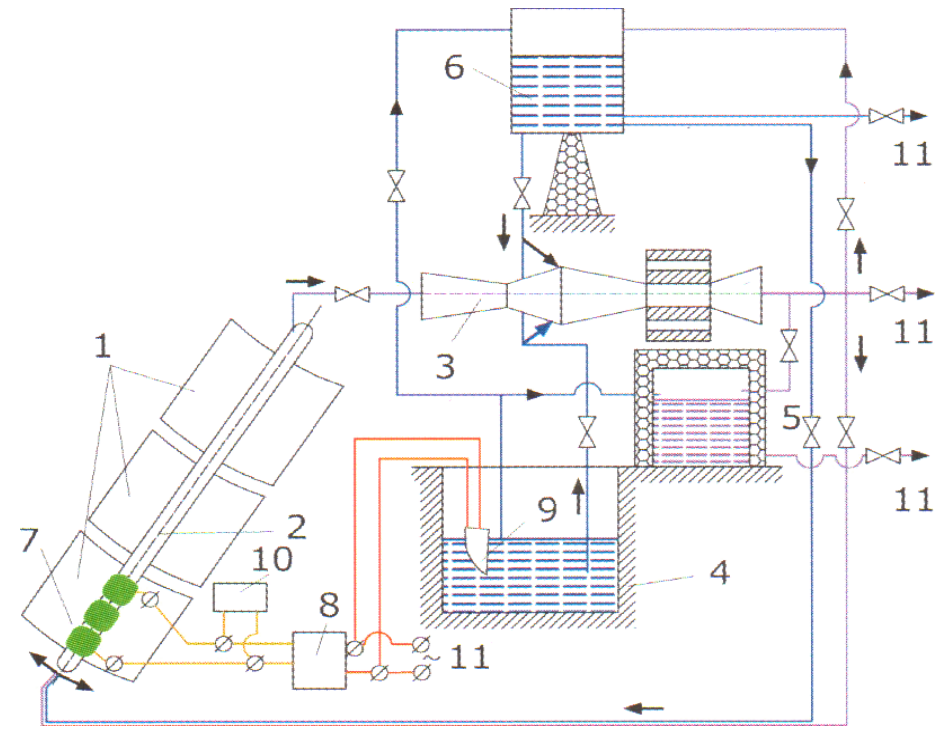

Figure 5. Diagram of solar plant with PT: 1 - parabolic trough, 2 - heat collecting element, 3 - jet pump. 4 - well, 5 and 6 - collecting tanks, 7 - photovoltaic array, 8 - inverter, 9 - submerged pump, 10 - accumulator battery, 11 - power and water supply to customer 
The functioning of plant in Fergana was described in (Kabakov V.I., Usanov V.V., 2003, pp. 89-105 and Kabakov V.I., Kokhova I.I., Drobiazgina O.N., 1989, no. 3). The steam-water mixture formed in receiver is coming to JP, where the cold water from well is also pumped. The water from tank 6 and changeable set of diffuser throat are used for JP startup. The liquid after JP has a pressure exceeding the initial pressures at entrance in 3-4 times that allows to pump the water in the accumulator tanks as well as to consumer and to the entrance of solar receiver. The plant in Figure 5 is supplemented by the duplicating water-lifting photovoltaic system providing as well the operation of tracking system and power supply of customer. When it is necessary, the pumps in plant could work simultaneously or alternatively. The plant allows accumulating energy in the form of heated and lifted water in tanks 5 and 6 . The PV array allows using the water lifting by means of PT and JP in the periods of sufficient solar radiation, while the electricity obtained from them is stored in accumulation batteries. The submerged pump should be used for water lifting under not sufficient solar radiation

Thus, the functional abilities of plant, its reliability and efficiency are increased due to PVA (PV array) installed at the solar receiver, while the maximum uninterruptedness of plant operation and a possibility of power-, heat and water supply of customer are achieved due the usage of electricity storage and accumulators of lifted cold and heated in JP water.

When the PVA is working in the concentrated solar light, their number is decreased for the same output in the case of non-concentrating work, while its installation at receiver of the first PT module provides their optimal cooling. The optimal pointed location of PVA at PT receiver secures their uniform illuminance by concentrated light, which is necessary for their reliable and efficient operation. Such operation of PVA and their satisfactory cooling were confirmed by theoretical calculations and in experiments (Kabakov V.I., 2014, pp.12-17 and Kabakov V.I., Levin L.B.., Sereda I.P., Dodonov L.D., 1994, pp. 802-808).

The availability of water-lifting plant with PT and JP as well as its reliability and full autonomy were confirmed by its operation in the different places of Uzbekistan (Central Asia) or in Transbaikalia (Russia), where the demands of such plants in the remote regions of glazing livestock constitute the tens of thousands (Kabakov V.I., 2014, p.105).

Some problems, which are currently relevant for the large parabolic trough and tower power plants were successfully solved at the solar plant under consideration and in the corresponding investigations. They include: the adjustment of optical system by using the flexible cables, tension bracings and screw bolts; the usage of store batteries for prolongation of the time of customer service with insufficient or absent solar radiation; the hybrid solar power plants (with additional fuel or photo-thermodynamic ones); the optimal construction of vacuum heat collecting element (HCE) and the application of liquid injection through the holes and swirl for optimization of heat- and mass transfer in HCE for improving its characteristics; the efficient high-temperature heat carrier with black dye - such heat carrier, which in contrast to the known heat carrier being the melt of $\mathrm{Na}$ and $\mathrm{K}$ salts has the substantially lower freezing point.

The plants containing two JP were suggested and patented by author for desalination and increasing the depth of water lifting from the well (in solar variant), and as well - for the operation together with heat pump or brine delivery for its reinjection or in the unit for extracting the valuable mineral (a geothermal variant). However they are not under consideration in this article.

\section{Geothermal Plant with Jet Pumps for Water- and Heat Supply and Other Purposes}

JP in geothermal plants, similar to its functioning in solar plants, fulfils the functions of water lifting from a source and its supply to consumers being simultaneously the mixer, heat exchanger and condenser. In the same time the JP heats the lifted water and pumps it. In addition JP in geothermal plants reduces by means of fresh water the final mineralization.

The results of tests in Central Asia and Kamchatka didn't reveal any deviations from the results of laboratory investigations (Kabakov V.I., 2011, pp. 60-66). Only a possibility for JP to work with the saline mineralized brines was discovered. The small laboratory constructions of injectors had been calculated and intended for small flow rates (the exit flow rate was from 1 or less $t / h$ up to $10 \mathrm{t} / \mathrm{h}$ ). The pumps with capacities from 20 to $60 \mathrm{t} / \mathrm{h}$ were required for covering the demands in heat and hot water supply of local settlement of drilling technicians at Kamchtka, while the capacity of JP for solar plants shouldn't exceed 0.5-0.6 т/ч because of limited amount of water in the wells.

Three different JP constructions were designed, developed and manufactured for the operation at Kamchtka. After long and difficult way and mounting at the place they were tested and have worked at Pauzhtskoye geothermal field: JP-312 with multispray liquid injection for $20 \mathrm{t} / \mathrm{h}$, as well as JP-315 and JP-316 - for $60 \mathrm{t} / \mathrm{h}$ each (SP -315 had the same multispray injection, while JP-316 had a central supply of cold water). 
The method corresponding to the operations sequence at the block-diagram (Figure 3) was used in the development of JP constructions. The results of testing two-phase and liquid nozzles allowed to determine their length and the area of exit cross-sections as well the area on the entrance to mixing chamber. The length and diameters of mixing chamber and diffuser were determined by using the results of liquid jet spreading in the two-phase flow and the condition of appearing pressure shock in the diffuser throat (dt). The constructions of JP with central and multi-spray supply of liquid were tested in the laboratory and filed conditions.

The schematic diagram of plant for testing and operation of three large pumps JP-312, JP-315 and JP-316 at Kamchatka are presented at Figure 6. The tests and operation described in (Kabakov V.I., Usanov V.V., 2003, pp.89-105) were carried out with the initial pressure of steam-water mixture (SWM) 0.06-0.25 MPa, its steam quality 0.04 and initial enthalpy $55 \mathrm{~kJ} / \mathrm{kg}$, cold water temperature $5-20^{\circ} \mathrm{C}$, and hot brine temperature supplied in the second stage (through the hole for startup) - up to $95^{\circ} \mathrm{C}$. SWM 3 after geothermal well 1 came to JP-312 4, JP-315 5 and JP-316 6. The cold water came from the small local river 10, while it flow rate was determined by flow meter 13 . The exit after separator 2 was connected with the second inlet 11 of jet pumps, which sucked simultaneously the cold and hot water in mixing chamber and supplied water with necessary temperature and low mineralization (it was reduced in JP in 3-4 times) to the customers 7 - in the settlement of drilling technicians and the local greenhouses.

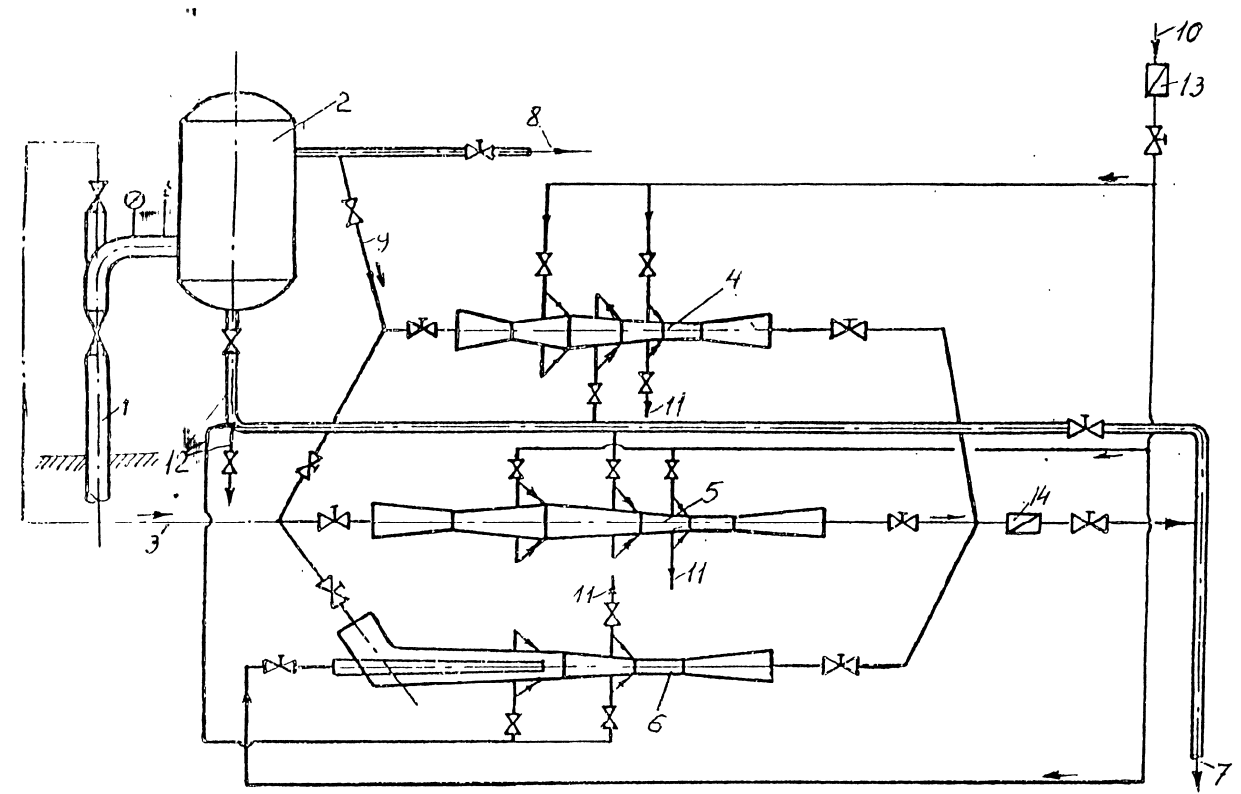

Figure 6. Schematic diagram, of plant for testing and maintenance of jet pumps at the well K-16 of Pauzhetskoye geothermal field

The utilization of JP for pumping the hot brines, i.e. as the pumps for such mineralized liquids, distinguishes these tests from laboratory ones and shows the new abilities of these devices. The large JP allowed supplying to consumer up to $60 \mathrm{t} / \mathrm{h}$ of water each with temperature $35-95^{\circ} \mathrm{C}$. Additionally in contrast to the laboratory tests, the successful operation of the same JP was reached at Kamchatka with the direct steam supply (9) from separator (2). I.e. JPs allowed to utilize the steam after waste well that represent as well the method of removing the heat pollution of environment (8).

In this case, the important result of laboratory and field tests was the fact that no any differences in the operation and characteristics of large and small JPs had been found with the same parameters of flows at the entrance. Therefore the effect of scale factor on the final characteristics of JP was not revealed. The initial and exit pressures as well the dimensionless numbers in the formulae presented above were the same, and it concerns also the efficiencies of large and small JP. As to the sizes, the length of large JP constituted 2-4 m, while for small JP it didn't exceed $0.3 \mathrm{~m}$.

\section{The Main Results of Laboratory and Field JP Tests}

The results of laboratory and field JPs tests in ENIN, Fergana and at Kamchatka are presented in Figure 7. 


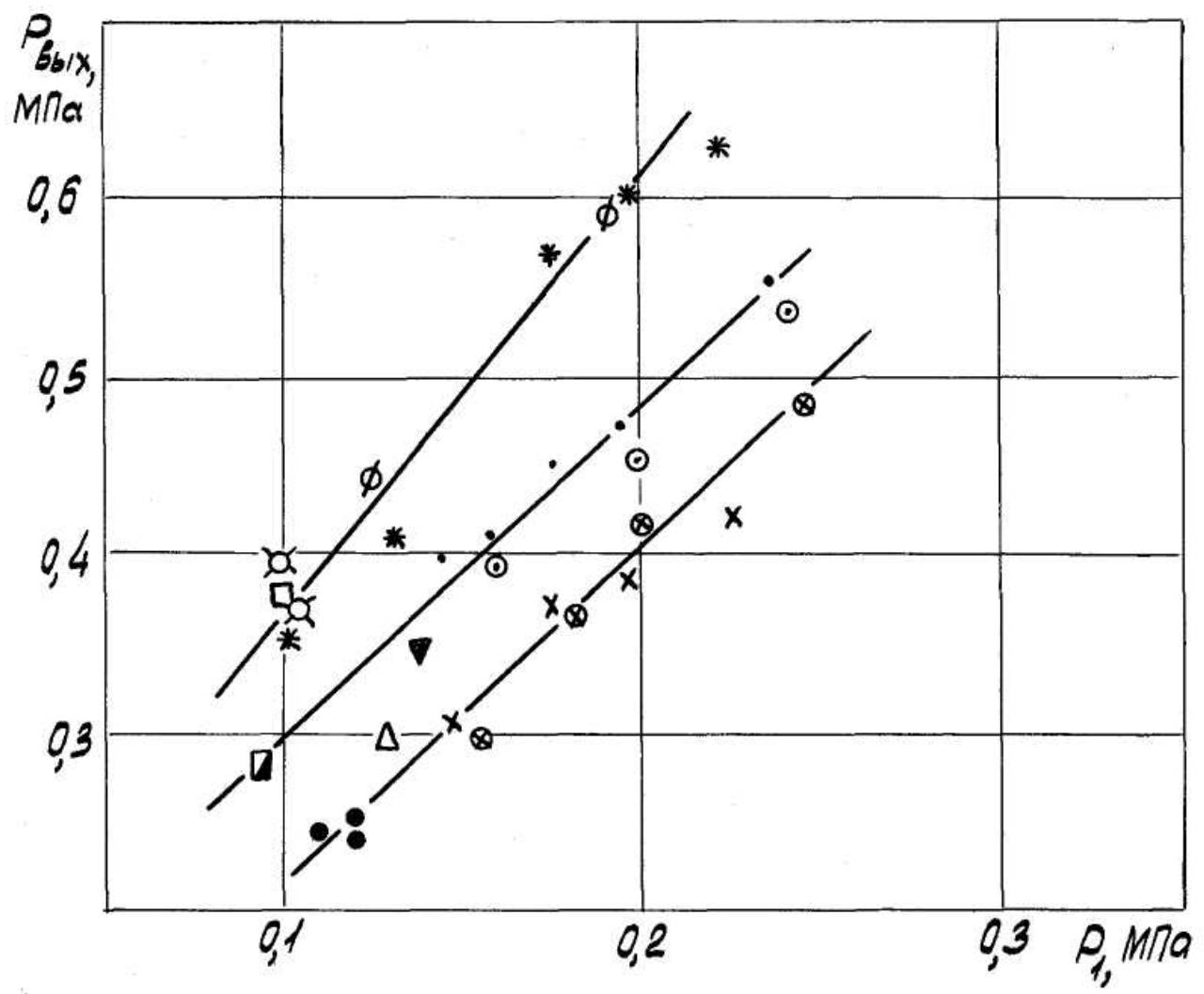

Figure 7. Dependence of exit liquid pressure on the initial pressure of mixture for different designs of injectors and jet pumps at the test desk (ENIN), at the geothermal wells RE-1 and K-I6 (Pauzhetka) and as a part of solar plant in Fergana

- - injector with $\mathrm{d}_{\mathrm{dt}}=4 \mathrm{~mm}$ and

- injector with $\mathrm{d}_{\mathrm{dt}}=3.5 \mathrm{~mm}$ $\circledR$ and $\mathrm{x}$ - injector with $\mathrm{d}_{\mathrm{dt}}=6 \mathrm{~mm}$ and

$\odot$ and $\bullet-$ injector with $\mathrm{d}_{\mathrm{dt}}=5,2 \mathrm{~mm}$

$\varnothing-$ injector with central supply of

liquid: $\quad d_{\mathrm{ln}}=6 \mathrm{~mm} ; \quad d_{\mathrm{dt}}=5 \mathrm{~mm}$

* - jet pump JP-312: $d_{\mathrm{dt}}=14 \mathrm{~mm}$

$\boldsymbol{\nabla}$ - jet pump JP-312: $d_{\mathrm{dt}}=17 \mathrm{~mm}$;

$\Delta$ - jet pump JP-312: $d_{\mathrm{dt}}=20 \mathrm{~mm}$;

- jet pump JP-315: $d_{\mathrm{dt}}=40$ мм и

$\square$ - jet pump JP-316: $d_{\mathrm{ln}}=25 \mathrm{~mm}, d_{\mathrm{dt}}=40 \mathrm{~mm}$ solar plant

test desk (results in circles) and well RE - 1

и

- well RE - 1

- well K - 16

The comparison of testing data for the pumps with central and multijet cold water supply operating as a part of plants developed and created at Kamchatka and Central Asia with the testing results obtained before in ENIN as well as at Kamchatka and Fergana with less in capacity (for Kamchatka) or larger in capacity (for solar plants) and correspondingly in sizes the laboratory JPs is carried out in Figure 7. All presented data were obtained for the maximum pressure $p_{\text {exit }}$ preceded to the disruption. It should be noted that the numerous results of JP tests in ENIN and under natural conditions showed that such presentation of results as in Figure 7, allows determining the same tendencies that are revealed in analyzing the change of inner and total efficiency of these devices.

It is possible to conclude from Figure 7 that:

1) The best and same results (upper curve) were obtained at Kamchatka with the central liquid injection in the 
laboratory construction and similar pump JP -316;

2) Almost the same results were obtained for multijet injection with the pump JP -312 having the multijet supply and small diffuser throat (14 MM) and the large JP-315 that confirms the activity of calculation method and a method of JP design, which allowed to receive JPs sizes and form;

3) A curve 2 concerns the tests of multijet injector with $d_{\mathrm{dt}}=5.2 \mathrm{~mm}$ and pump JS-312 with $d_{\mathrm{dt}}=17 \mathrm{~mm}$ and in laboratory and at Kamchatka. The data for JP of solar plant tested in Fergana with small $d_{\mathrm{dt}}=3.5 \mathrm{~mm}$ are also presented. Hence, the indicators of multijet injectors with capacities $0.5,20$ and $50 \mathrm{t} / \mathrm{h}$ calculated by the same method agreed on the whole that confirms the efficiency of calculation method (Kabakov V.I., Zheltova G.M., 1988, pp. 139-150) and the absence of scale factor effect on JPs indicators in the range of main operating and construction values;

4) The lower curve concerns the JP of solar plant with $d_{\mathrm{dt}}=4.0 \mathrm{~mm}$ and other multijet devices - the laboratory construction with $d_{\mathrm{dt}}=6.0 \mathrm{~mm}$, the results at testing rig and at a well RE-1 coincided completely, and to the JP-312 with $d_{\mathrm{dt}}=20 \mathrm{~mm}$. The testing data for JP-312 with different throats $\left(d_{\mathrm{dt}}=14,17\right.$ and $\left.20 \mathrm{~mm}\right)$ pointed out the considerable effect of throat size at JP operation.

The problems solved by using geothermal plant include also: the substitution of large electric pumps for aggressive media by the jet vacuum-pressure pumps; the reduction of brine mineralization in 3-4 times that makes them corresponding to the medical standards; the possible supply of brines in the apparatus for extracting the valuable materials from them; the removal of harmful environmental impact of steam and brine [2].

The test and consequent maintenance of JPs showed their availability for solving the goal, for which they intended, while the calculated JP capacities achieved in reality are approaching one to another. The scales at the surfaces of large JPs during their testing at Kamchatka, which exceeded in time 300 hours for each pump, was not observed even in the case, when in addition to the main supply of fresh water the hot mineralized brine after separator of well K-16 was injected through the startup holes, and the jet pumps become the pumps of hot mineralized liquid. The flow rate of hot water through these holes constituted in the conditions under consideration approximately the same value $G_{1}$, as the flow rate of cold water through the first stage of injection. It should be noted that the amount of mineral salts in the brine of well K-16, where the large JP-315 and JP-316 were tested and operating was not high and constituted about $1940 \mathrm{mg} / \mathrm{l}$, i.e. was approximately twice lower that at the other well RE-1. Nevertheless, in this case, when the mineralized liquid was supplied in the second stage, the total mineralization at the exit was twice less or a third of the value pointed for the brine. It should be noted that the well K-16 before its utilization together with JPs was waste and the steam after it emitted to atmosphere. I.e. the ecological effect of using the jet pumps consisted of the removal of steam, heat and chemical environmental. The pumps JP-315 and JP-316 at the well K-16 (Figure 6) as the small JPs at solar plant in Fergana provided almost fourfold increase of exit pressure in comparison with the entrance values for SWM and liquid.

\section{Conclusion}

1). The method for choosing the diagram and calculation of constructions and geometric sizes of solar and geothermal plants with jet pump for concrete specified purposes was developed by means of theoretical results and the results of experimental investigations of plants and their elements as well as studying their operation in laboratory and field condition and the physical processes in their elements.

2). The additional goals of application were suggested and realized in addition to the main purposes of utilization for water-lifting, water- and heat supply in dependence on the parameters of media at the entrance in plants. In particular, it was the combined or hybrid use of photovoltaic and thermodynamic conversion methods in one solar plant that allows to made the functioning of such plants fully autonomous and to have the power supply of consumer. Another suggestion allows to increase the depths of water lifting or to use the solar plant efficiently for desalination (Kabakov V.I., 2011, pp.60-66; Kabakov V.I., 2008, pp. 70-76; Kabakov V.I., 2012. pp. 263-274).

3). The geothermal variant of plant with jet pumps allowed in addition to the water and heat supply to neutralize the negative environmental impact and to reduce the mineralization of ware supplied to customers up to the required standards. A possibility of using JP of pumping the brines is first shown that allows not to use the large-scale centrifugal electric pumps and to reinject the brine in the field stratum or in the plant for extracting the valuable elements and materials from it.

4). The calculations showed that in such remote regions far from the centralized fuel and power supply, where the cost of fossil fuels and electricity rates are high, such plants with using the waste wells are efficient and have the small payback period (Kabakov V.I.,2014,p.105). 


\section{References}

Kabakov V.I. (2006). Ecologically clean geothermal water and heat supply plants with jet and heat pumps. Proc. of Conference "Renewable energy 2006, Advanced Technology path to global Sustainability, Chiba, Japan.

Kabakov V.I. (2008). Power plant using solar energy. Electric power stations, (9), 70-76.

Kabakov V.I. (2011). Hybrid plants with jet pumps. Small energy, (3-4), 60-66.

Kabakov V.I. (2012). Methods for intensifying parabolic trough receivers operation. Int. J. of Technology, Policy and Management. 12(2/3), 263-274. http://dx.doi.org/10.1504/IJTPM.2012.046930

Kabakov V.I. (2014, April). Progress in development of solar plants with concentrators. ENERGY-FRESH, 12-17.

Kabakov V.I. (2014, July). Plants working with RES for solving the concrete local problems. $2^{\text {nd }}$ International Forum in Chernogolovka "Renewable energy. Applied aspects of development and practical usage", p.105.

Kabakov V.I., \& Usanov V.V. (2003). Prospects of using jet devices for solving ecological problems. Int. J. of Environmental Technology and Management, 3(1), 89-105. http://dx.doi.org/10.1504/IJETM.2003.002373

Kabakov V.I., \& Yeroshenko V.M. (2012). Development and use of different accumulators in solar plants with concentrators. Alternative energy and ecology, (3), 39-44.

Kabakov V.I., \& Zheltova G.M. (1988). Method of calculating the condensing injector and some method of its optimization. Collected article of ENIN "Thermal and hydrodynamic processes in elemens of power equipment of electric power stations", 139-150.

Kabakov V.I., Kokhova I.I., \& Drobiazgina O.N. (1989). Solar plant for water lifting and desalination. Technique in agriculture, (3).

Kabakov V.I., Levin L.B.., Sereda I.P., \& Dodonov L.D. (1994). A choice of form and temperature regimes in photothermal receiver of parabolic trough. $7^{\text {th }}$ Int. Symp. On Solar Thermal Concentrating Technologies, 802-808.

Trusov V.P., Kabakov V.I., Sorokin A.I, Shabanov A.A, \& Milman N.A. (1995). Small geothermal plants on the basis of application of common flow conservation. Material of World Geothermal Conference, Florence, Italy, 3, 2119-2124. 